\title{
Stacking Effect of Polyfluorene on the Chemical Shift and Electron Transport
}

Woo Seong Kim, Jongseob Kim ${ }^{* \dagger}$, Jong Keun Park, Shaul Mukamel, ${ }^{\ddagger}$ Soon Ki Rhee, Yong Kook Choi, and Jin Yong Lee

Department of Chemistry, Chonnam National University, 300 Yongbong-Dong, Bugku, Gwangju, 500-757, Korea, Computational Science Engineering Center, Samsung Advanced Institute of Technology, P. O. Box 111, Suwon 440-600, Korea, and Department of Chemistry, University of California, Irvine, Irvine, California 92697

\section{Supporting Information}

\section{Contents}

1. B3LYP/6-31G* optimized structures without symmetry $\left(\mathrm{C}_{1}\right)$ of $\mathbf{F 1}, \mathbf{F 2}$, and F3. (These structures were used for NMR chemical shifts, absorption spectra, and transition densities. See the Scheme.) (Figure S1)

2. B3LYP/6-31G* optimized structures of syn and anti configurations with $\mathrm{C}_{\mathrm{s}}$ symmetry of F2. (Figure S2)

3. B3LYP/6-31G* optimized structures of syn and anti configurations with $\mathrm{C}_{\mathrm{s}}$ symmetry of F3. (Figure S3)

4. B3LYP/6-31G* optimized structures of syn and anti configurations with $\mathrm{C}_{\mathrm{s}}$ symmetry of F4. (Figure S4) 


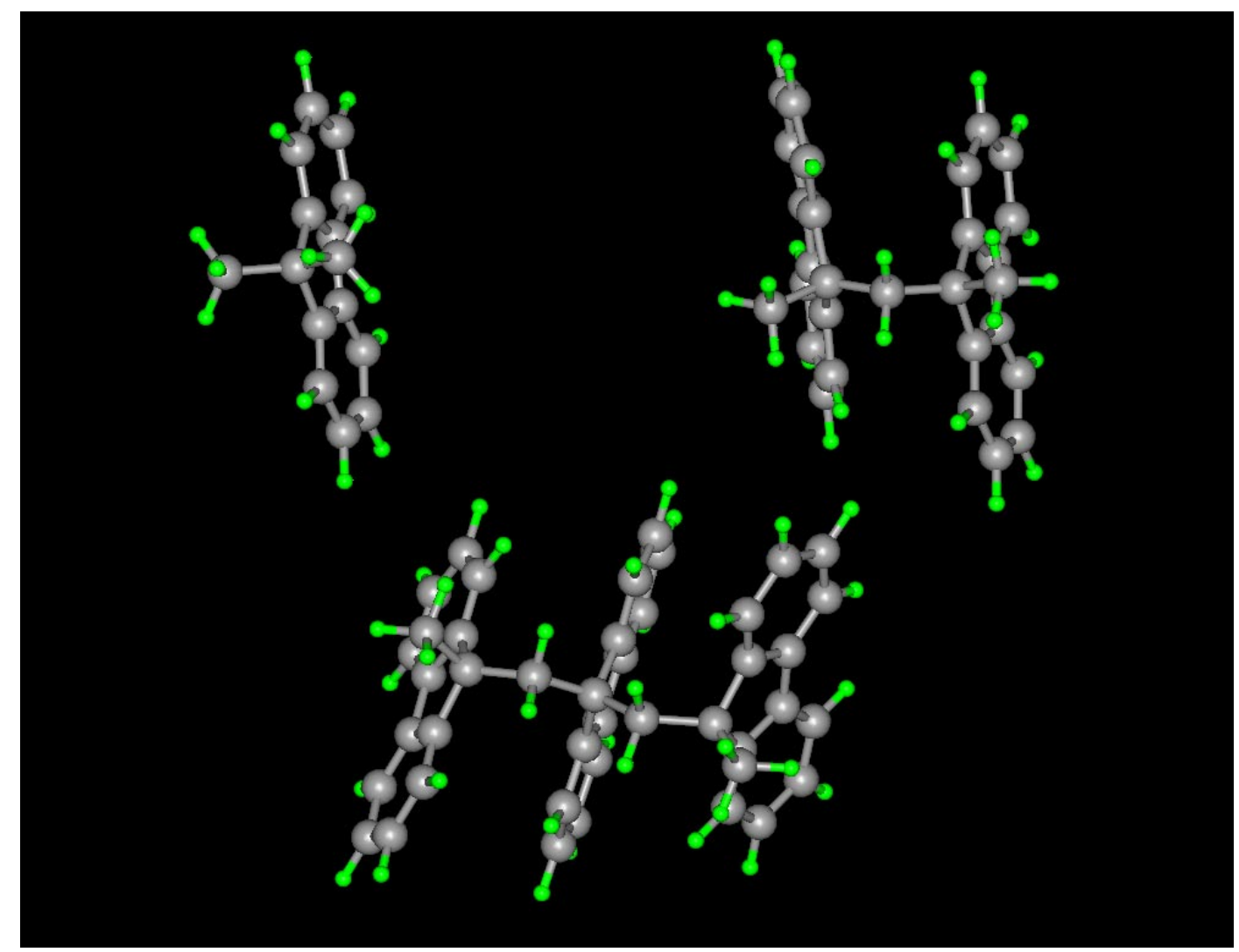

Figure S1. B3LYP/6-31G* optimized structures without symmetry $\left(\mathrm{C}_{1}\right)$ of $\mathbf{F 1}, \mathbf{F} 2$, and F3. F2 and F3 show the slightly displaced structures. (These structures were used for NMR chemical shifts, absorption spectra, and transition densities. See the Scheme.) 


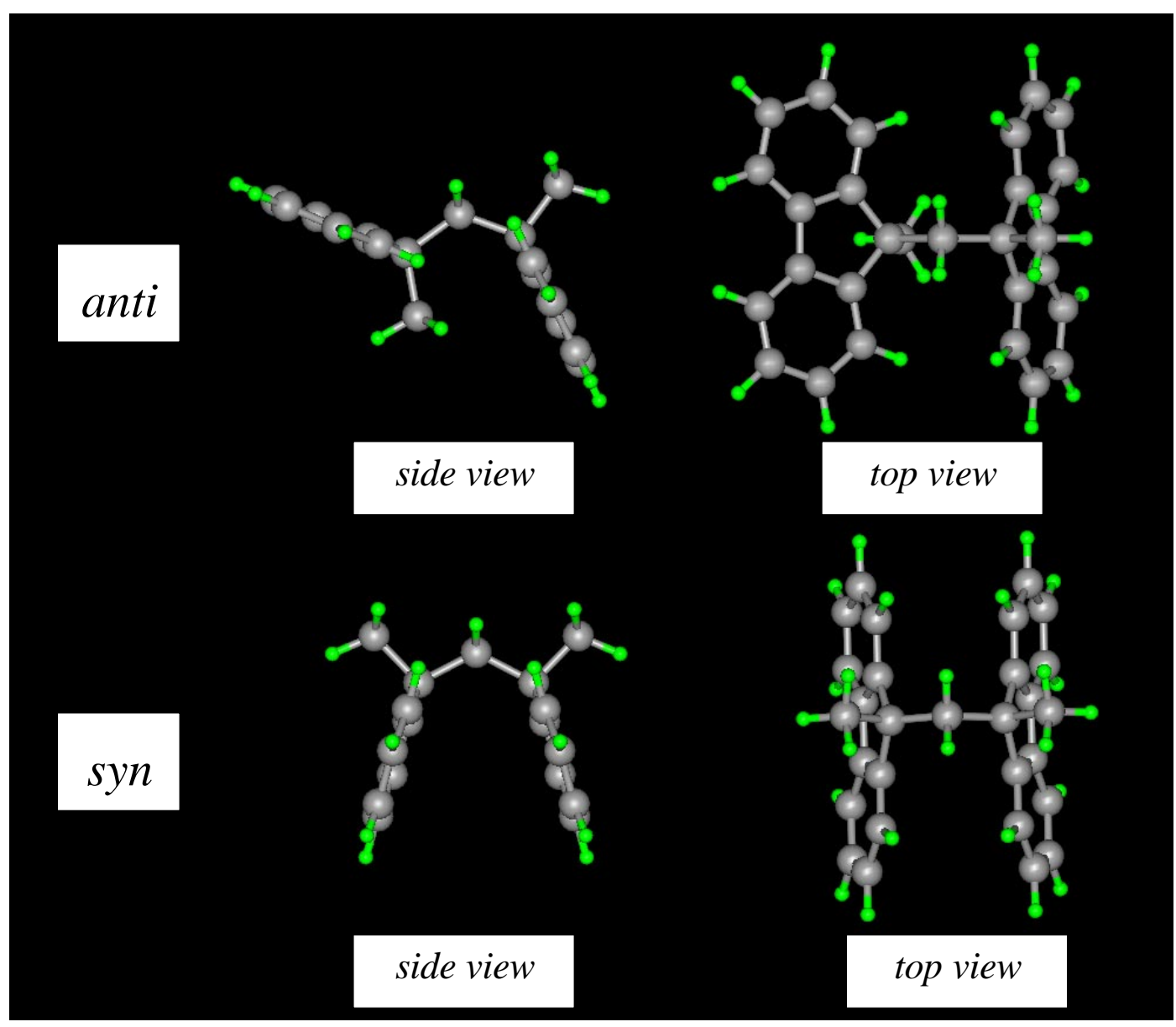

Figure S2. B3LYP/6-31G* optimized structures of syn and anti configurations with $\mathrm{C}_{\mathrm{s}}$ symmetry of $\mathbf{F 2}$. 


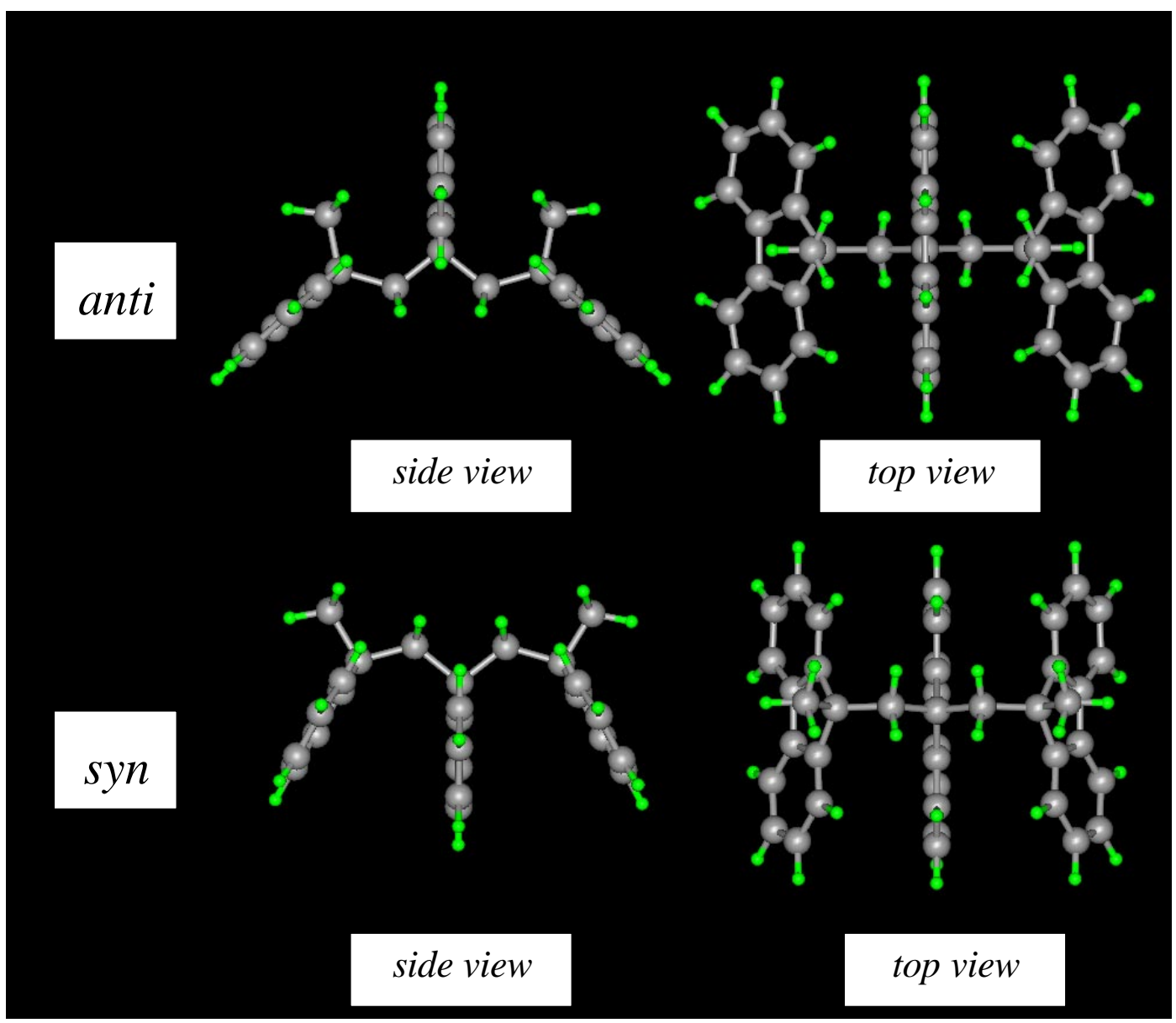

Figure S3. B3LYP/6-31G* optimized structures of syn and anti configurations with $\mathrm{C}_{\mathrm{s}}$ symmetry of $\mathbf{F 3}$. 


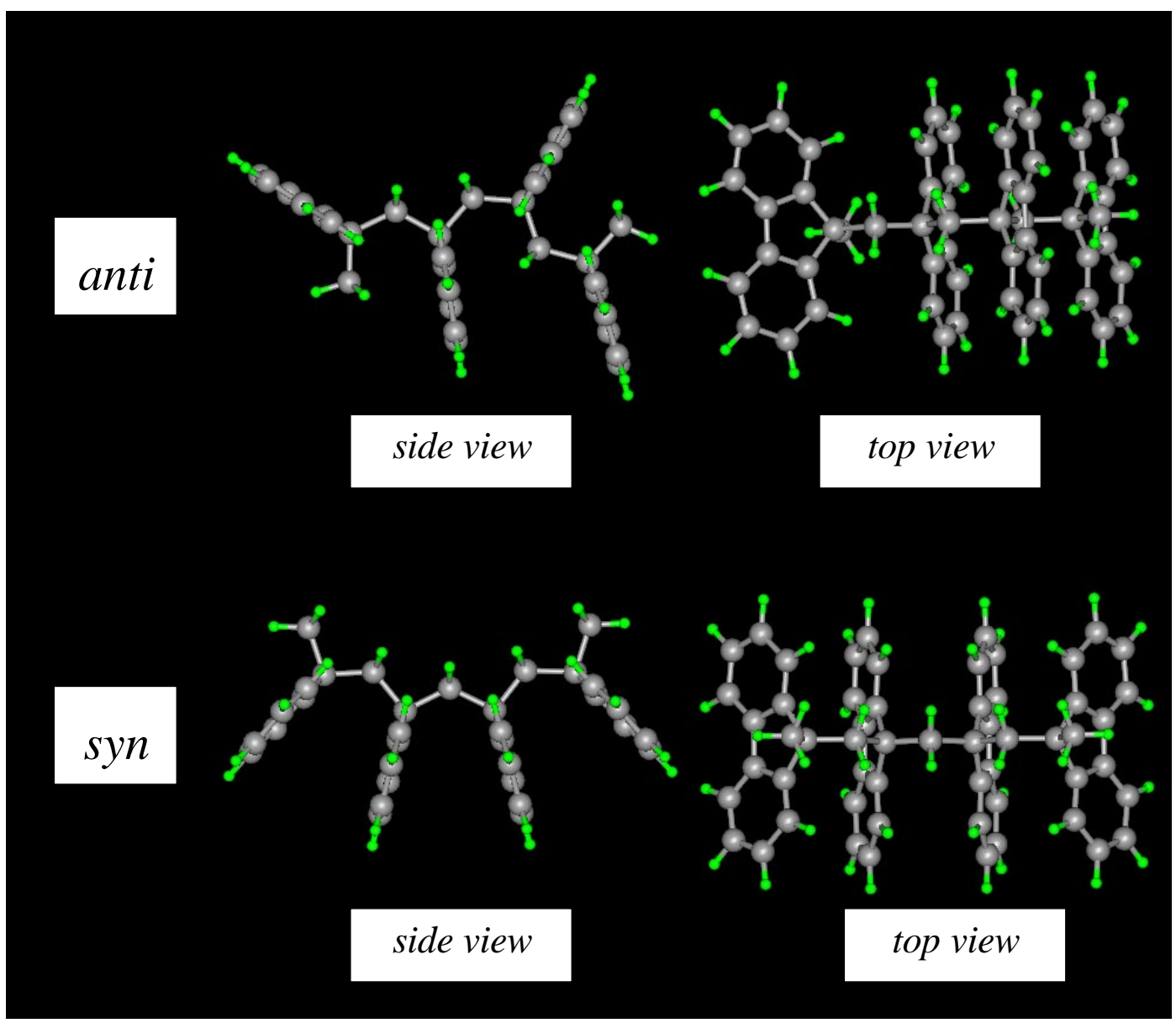

Figure S4. B3LYP/6-31G* optimized structures of syn and anti configurations with $\mathrm{C}_{\mathrm{s}}$ symmetry of $\mathbf{F 4}$. 